\title{
The Predictability of Returns on Equity REITs and Their Co-Movement with Other Assets
}

\author{
Crocker H. Liu, New York University \\ Jianping Mei, New York University
}

\begin{abstract}
Recent evidence suggests that the variation in the expected excess returns is predictable and arises from changes in business conditions. Using a multifactor latent variable model with time-varying risk premiums, we decompose excess returns into expected and unexpected excess returns to examine what determines movements in expected excess returns for equity REITs are more predictable than all other assets examined, due in part to cap rates which contain useful information about the general risk condition in the economy. We also find that the conditional risk premiums (expected excess returns) on EREITs move very closely with those of small cap stocks and much less with those of bonds.
\end{abstract}

Recent evidence suggests that the variation in the expected excess returns over time is predictable and is the result of changes in business conditions. ${ }^{1}$ We offer further evidence on this issue by extending the previous literature to include real estate, particularly equity real estate investment trusts (EREITs). ${ }^{2}$ What is unique about EREITs is that it is traded as a stock on a stock exchange but represents an underlying ownership in a portfolio of real estate. This feature raises the possibility that different variables may be required to capture the time variation in its risk premiums relative to those for bond and non-REIT stocks. Another issue related to the hybrid nature of EREITs is whether EREITs are a hybrid of stocks and bonds and whether the stock component is representative of large cap stocks or small cap stocks. More specifically, the questions addressed in this article include: (1) Do the same variables forecast stocks, bonds, and real estate returns so that the expected returns (conditional risk premiums) on these assets move together? In particular, do cap rates carry information about the conditional risk premium for equity REITs but no other asset class? (2) Is the variation in the expected returns on equity REITs related to business conditions? (3) To what extent do REITs resemble stocks with large capitalizations, stocks with small capitalizations, and bonds? 
While Mengden and Hartzell (1986), Giliberto (1990), and Corbel and Rogers (1991), among others, have studied the hybrid nature of REITs in the past, none of these studies focuses on the predictability of EREIT returns. Prior REIT studies have also looked at returns on broad asset market classes such as stocks and bonds to explain REIT fluctuations rather than looking at business conditions that influence expected returns on all asset classes. ${ }^{3}$ In addition to this, prior studies have not examined small cap stocks as a hybrid component of REITs even though REITs have low capitalizations relative to the overall stock market. The typical two-stage procedure used in the past to examine the hybrid nature of the REIT involved imputing a real estate index by using the residuals from a regression of the returns on an EREIT portfolio on a stock market proxy. Equity REITs were then regressed against a stock market portfolio and this real estate market portfolio. If the beta was positive on the stock market proxy and zero for the real estate proxy, then the conclusion was that REITs resemble stocks. However, several problems temper the findings of these studies, including the implicit assumption that the returns of the "true" market in-^ dices are observable and the fact that errors-in-variables arise as the result of the two-pass estimation procedure. Moreover, purging the REIT portfolio of its correlation with the broader market eliminates important real-estate-related information if the argument of Geltner (1989) and Gyourko and Keim (1991), that common factors are likely to drive returns on both real estate and nonreal-estate related assets, are valid.

Our study employs a multifactor latent-variable model that allows us to study the time variation of expected excess returns on different asset classes and to address the issue of the resemblance of asset returns by comparing the similarities among assets by their return variation patterns. This methodology has several distinctive advantages over previous studies. First, it allows for time-varying risk premiums in contrast to the existing methodology that generally assumes constant risk premiums. Thus, it is designed to capture the time variation not only in unexpected excess returns but also in expected excess returns. Second, it makes no assumptions about the observability of systematic factors in the economy. Third, no other distributional assumptions on the error terms are required except those associated with Hansen's (1982) Generalized Method of Moments (GMM). The estimation procedure adjusts for heteroskedasticity in the error terms and permits contemporaneous correlation among the error terms across securities to exist. The GMM procedure also could adjust for a moderate amount of serial correlation in the returns which mitigates against the possibility that the predictability of asset returns is partly induced by serial correlation as a result of nonsynchronous trading.

The most interesting finding of our study is that expected excess returns for equity REITs are more predictable than large cap stocks, small cap stocks, and bonds. Returns on small cap stocks also 
exhibit a high degree of predictability. This increased predictability for equity REITs and small cap stocks is due in part to movements in the cap rate, a real estate business condition variable previously not used in previous studies. Besides this, we find that movements in the cap rate provide different information from that contained in dividend yield fluctuations with respect to equity REITs, even though this is not necessarily the case with other asset classes that we examine. We also find that equity REITs resemble small cap stocks and to a lesser extent large cap stocks but have less in common with bonds. This implies that EREITs do not resemble bonds and therefore bonds are not part of the hybrid nature of equity REITs. Our study also finds that either a single-factor or two-factor latent variable model is representative of the data depending on the level of significance used.

The remainder of the article is organized as follows. Section 1 describes the asset pricing framework; a description of our dataset is contained in section 2. The existence of predictable excess equity REIT returns is documented in section 3, together with the extent to which equity REITs are a hybrid of large cap stocks, small cap stocks, and bonds. We also discuss the results of our latent variable model that restricts the expected excess returns on value weighted stocks, small cap stocks, equity REITs, and bonds to move together. Section 4 concludes the study.

\section{The Asset Pricing Framework}

The asset pricing framework used in this study assumes that capital markets are perfectly competitive and frictionless with investors believing that asset returns are generated by the following Kfactor model:

(1)

$$
\tilde{r}_{i, t+1}=E_{t}\left[\tilde{r}_{i, t+1}\right]+\sum_{k=1}^{K} \beta_{i k} \tilde{f}_{k, t+1}+\tilde{\epsilon}_{i, t+1} .
$$

Here $\tilde{r}_{i, t+1}$ is the excess return on asset $i$ held from time $t$ to time $t+1$, and represents the difference between return on asset $i$ and the riskfree rate of interest. $E_{t}\left[\tilde{r}_{i, t+1}\right]$ is the expected excess return on asset $i$, conditional on information known to market participants at the end of time period $t$. We assume that $E_{t}\left[\tilde{f}_{k, t+1}\right]=0$ and that $E_{t}\left[\tilde{\epsilon}_{i, t+1}\right]=0$. The conditional expected excess return is allowed to vary through time in the current model, but the beta coefficients are assumed to be constant through time.

This ability of $E_{t}\left[\tilde{r}_{i, t+1}\right]$ to vary through time is absent in prior REIT studies. ${ }^{4}$ However, if $E_{t}\left[\tilde{r}_{i, t+1}\right]$ is not restricted to be constant, then we need to look not only at the closeness of beta(s) but 
also the co-movement of $E_{t}\left[\tilde{r}_{i, t+1}\right]$ through time in analyzing the co-movement of excess returns on two or more assets. In other words, it is possible for the risk premiums and excess returns of two assets not to move together even though they have similar betas. However, this problem will not occur if the following linear pricing relationship holds:

(2)

$$
E_{t}\left[\tilde{r}_{i, t+1}\right]=\sum_{k=1}^{K} \beta_{i k} \lambda_{k t},
$$

where $\lambda_{k t}$ is the "market price of risk" for the $k$-th factor at time $t .^{5}$

Now suppose that the information set at time $t$ consists of a vector of $L$, forecasting variables $X_{n t}, n=1, \ldots L$ (where $X_{l t}$ is a constant), and that conditional expectations are a linear function of these variables. Then we can write $\lambda_{k t}$ as

(3)

$$
\lambda_{k t}=\sum_{n=1}^{L} \theta_{k n} X_{n t},
$$

and therefore equation (2) becomes

$$
E_{t}\left[\tilde{r}_{i, t+1}\right]=\sum_{k=1}^{K} \beta_{i k} \sum_{n=1}^{L} \theta_{k n} X_{n t}=\sum_{n=1}^{L} \alpha_{i n} X_{n t} .
$$

Equations (1) and (4) combined are sometimes called a multifactor "latent-variable" model ${ }^{6}$ The model implies that expected excess returns are time-varying and can be predicted by the forecasting variables in the information set. From equations (3) and (4), we can see that the model puts some restrictions on the coefficients of equation (4), which is that

(5)

$$
\alpha_{i j}=\sum_{k=1}^{K} \beta_{i k} \theta_{k j} \text {. }
$$

Here, $\beta_{i k}$ and $\theta_{k j}$ are free parameters. Normally, the $\left(\alpha_{i j}\right)$ matrix should have a rank of $P$, where $P$ is defined as $\mathrm{P}=\min (N, L)$. Equation (5) restricts the rank of the $\left(\alpha_{i j}\right)$ matrix to be $K$, where $K$ is smaller than $P$. To test the restriction in equation (5), we first renormalized the model by setting the factor 
loadings of the first $K$ assets as follows: $\beta_{i j}=1$ (if $j=i$ ) and $\beta_{i j}=0$ (if $j \neq i$ ) for $1 \leq i \leq K$. Next, we partition the excess return matrix $R=\left(R_{1}, R_{2}\right)$, where $R_{1}$ is a TxK matrix of excess returns of the first $K$ assets and $R_{2}$ is a $T x\{N-K)$ matrix of excess returns on the rest of the assets. Using equations (4) and (5), we can derive the following regression system:

(6)

$$
\begin{aligned}
& R_{1}=X \Theta+\mu_{1} \\
& R_{2}=X \alpha+\mu_{2}
\end{aligned}
$$

where $X$ is a $T X L$ matrix of the forecasting variables, $\theta$ is a matrix of $\theta_{i j}$, and $\alpha$ is a matrix of $\alpha_{i j}$. If the linear pricing relationship in equation (3) holds, the rank restriction implies that the data should not be able to reject the null hypothesis $H_{0} . \alpha=\theta \mathrm{B}$, where $B$ is a matrix of $\beta_{i j}$ elements. The objectives of the article are to use the regression system in equation (6) to see to what extent the forecasting variables, $X$, predict excess returns and to test the rank restriction. If the rank restriction is not rejected by the data, then we can use the beta estimates to address the asset resemblance issue.

\section{The Estimation Procedure}

The regression system of equation (6) given the restriction in equation (5) can be estimated and testing using Hansen's (1982) Generalized Method of Moments (GMM), which allows for conditional hetroskedasticity and serial correlation in the error terms of excess returns. A more detailed discussion of this estimation procedure is provided in the Appendix.

In our empirical work we use forecasting variables $X_{n t}$ which are known to the market at time $t$. They include a constant term, a January Dummy, the yield on one-month Treasury bill, the spread between the yields on long-term AAA corporate bonds and the one-month Treasury bill, the dividend yields on the equally weighted market portfolio, and the cap rate on real estate. The yield variable describes the short-term interest rate. The spread variable tells us the slope of the term structure of interest rates, and the dividend yield variable captures information on expectations about future cash flows and required returns in the stock market. These three variables have been used by Campbell (1987), Campbell and Hamao (1991). Fama and French (1988, 1989), Ferson (1989), Ferson and Harvey (1989), and Keim and Stambaugh (1986), among others. ${ }^{7}$ In addition, we also include the cap rate, which captures information on expected future cash flows and required returns in the underlying real estate market. $^{8}$ 
In general, we do not want to assume that we have included all of the relevant variables that carry information about factor premiums. Fortunately, the methods described above are robust to omitted information. ${ }^{9}$ It is also worth mentioning that the methodology adopted here has several distinctive advantages. First, the model allows for time-varying risk premiums. ${ }^{10}$ Second, we need no other distributional assumptions on the error terms except those made at the beginning of this section. Besides this, the estimation procedure adjusts for heteroskedasticity in the error terms, and it also allows for contemporaneous correlation among the error terms across securities. The procedure also tolerates a moderate amount of serial correlation in returns, which mitigates against serial correlation accounting for a portion of the predictability in asset returns.

\section{Data}

Stock prices, dividends, and returns on long-term U.S. government bonds are taken from the Center for Research on Security Prices (CRSP) monthly stock tape. We study a value-weighted stock index comprised of all New York Stock Exchange (NYSE) and American Stock Exchange (AMEX) stocks. This value-weighted stock index is biased toward stocks with large market capitalizations. To adjust for this bias, we also include a small cap stock index in our study. Both the value-weighted stock index and the small cap stock index are obtained the Ibbotson and Associates Stocks. Bonds, Bills, and Inflation series on CRSP. The government bond return series is from the data source, which is $I^{\wedge}$ forming a portfolio of treasury bonds with an average maturity of 20-years and without call provisions or special tax benefits. Finally, we construct equally weighted equity REIT return series using all equity REITs on the CRSP from January 1971 to December 1989. All equity REITs are included, not just those having a continuous price history over the period in question to avoid the problem of survivorship bias. The use of an EREIT portfolio (in addition to the GMM procedure) minimizes the problem of nonsynchronous trading since any autocorrelation associated with individual REIT returns is minimized. The EREIT portfolio consists of 50 equity REITs on average. Nonsynchronous trading can be a problem because it tends to increase the predictability of asset returns when it is present. A REIT is deemed to be an equity REIT if it is listed as such on at least two of the following three sources; (1) REITSourcebook published by the National Association of Real Estate Investment Trusts, Inc.; (2) The Realty Stock Review published by Audit Investments; and (3) Moody's Bank and Finance Manual, Volume 2.

The yield on the one-month Treasury bill, the spread between the yields on long-term AAA corporate bonds and the one-month Treasury bill, and the dividend yields on the equally weighted market portfolio are obtained from Federal Reserve Bulletin and Ibbotson and Associates (1989). 
Monthly cap rates on real estate are taken from the American Council of Life Insurance publication Investment Bulletin: Mortgage Commitments on Multifamily and Nonresidential Properties Reported by 20 Life Insurance Companies ${ }^{11}$ The cap rate is defined as the ratio of net stabilized earnings to the transaction price (or market value) of a property. Net stabilized means that the income figure used in the numerator of the ratio assumes that full lease up of the building has occurred such that the building's vacancy is equal to or less than the vacancy of the market. Alternatively, the cap rate can be thought of as the earnings-price ratio on direct real estate investment. We include the cap rate as a forecasting variable since we hypothesize that movements in the cap rate do not necessarily contain the same information as fluctuations in the dividend yield on the stock market. Although both the cap rate and dividend yield are measures of income-to-value, the cash flows of buildings are not identical to the cash flows of firms that occupy space in the buildings. The cash flows of tenants are likely to be more variable than the cash flow for the building that they occupy since rents are a fixed cost to tenants in the short run given the long-term nature of most leases. ${ }^{12}$

\section{Empirical Results}

Table 1 provides summary statistics on the behavior of the excess return for each of our four asset classes as well as on our forecasting variables. For each variable, we report the mean, standard deviation, and the first order autocorrelation. An inspection of table 1 reveals that equity REITs have a much higher excess return relative to all other stocks and government bonds. More specifically, the mean excess returns on EREITs are 10 basis points higher than small cap stocks and 46 basis points higher than large cap stocks per month. Moreover, more than 70 basis points separate returns on EREITs

from returns on government bonds. Not only is the mean excess return on EREITs higher on average but also the standard deviation is lower than all other assets examined except for government bonds. In other words, EREITs have a higher mean excess return on average but smaller total risks (as measured by standard deviation) relative to all other assets, which is consistent with prior research. In addition, the returns on all assets exhibit positive first order autocorrelation. This is also consistent with prior studies, which discover that the excess returns on stock indices display short-run positive autocorrelation.

Table 1 also reports the correlations of returns among four asset classes. As expected, the excess returns on EREITs are highly correlated with small cap stocks since EREITs have relatively low market capitalizations even though EREITs appear to be superior to small cap stocks from a risk-return standpoint. EREITs are also correlated to a lesser extent with value-weighted stocks but have a low 
correlation with bonds. Although it is tempting here to conclude from the correlation matrix that EREITs are much closer to stocks than to bonds, a closer look at the return generating process reveals that the correlation between two types of assets in the economy can come from two sources, the co-movement of expected returns and the co-movement of unexpected returns, in general, it is possible for two assets to have high correlations but with neither their expected excess returns moving together. Only under the null hypothesis, where the expected returns are restricted by equation (2), do high correlations imply that the two parts move together across the two assets.

Table 2 reports the results of regressing excess assets returns on five forecasting variables and a constant term - a January dummy, returns on Treasury bills, the spread, the dividend yield on the equally weighted market portfolio, and the cap rate. The first four variables have been used in previous studies for forecasting U.S. stock returns with regression system (6) employed without the rank restriction. The most interesting finding in this table is that a larger component of the excess return on EREITs is predictable relative to all other assets. In particular, approximately 17.5 percent of the variation in monthly excess returns on EREITs is accounted for by our five forecasting variables. Returns on small cap stocks also exhibit a large predictability component (16.5 percent) whereas the returns on value-weighted stocks and government bonds are roughly 50 percent less predictable than the returns on EREITs or small cap stocks. The predictability of stocks and bonds found here is consistent with previous studies of Campbell and Hamao (1991) and Harvey (1989), among others. What is interesting is the high predictability of excess returns on EREITs and the similarity of EREITs to small cap stocks.

Table 1 Summary Statistics

\begin{tabular}{lccc}
\hline & Mean & S.D. & $\rho_{1}$ \\
\hline Dependent variables & & & \\
Excess return on value-weighted portfolio (VW) & 0.268 & 4.866 & 0.055 \\
Excess return on REITs portfolio (REITs) & 0.729 & 4.964 & 0.112 \\
Excess return on government bond portfolio (Bond) & 0.022 & 3.327 & 0.058 \\
Excess return on small stock portfolio (SS) & 0.628 & 6.695 & 0.113 \\
& & & \\
Forecasting variables & & \\
Yield on one-month T-bill (TB) & 7.537 & 2.775 \\
Yield spread between AAA bond and T-bill (SP) & 2.336 & 1.851 \\
Dividend yield on equal-weighted portfolio (DY) & 3.105 & 0.605 \\
Capitalization rate on equity REITs (CAPR) & 10.460 & 1.166 & 0.750 \\
\hline
\end{tabular}

Notes: The sample period for this table is 1972.1-1989.4, with 208 observations. Units on excess returns are percentage per month. Units on one-month T-bill rate, yield spread, and dividend yield are percentage per annum. $\rho_{1}$ is the first autocorrelation of the series. 
Correlations Among Dependent Variables

\begin{tabular}{llcrr}
\hline & EW & REITs & Bond & SS \\
\hline EW & 1.000 & 0.655 & 0.322 & 0.849 \\
REITs & & 1.000 & 0.179 & 0.802 \\
Bond & & 1.000 & 0.181 \\
SS & & & 1.000 \\
\hline & & & & \\
& Correlations & Among Independent Variables & \\
\hline & T-Bill & Spread & Div. Yld. & Cap Rate \\
\hline T-Bill & \multirow{2}{*}{1.000} & -0.558 & 0.473 & 0.704 \\
Spread & & 1.000 & -0.393 & -0.317 \\
Div. Yld. & & 1.000 & 0.546 \\
Cap Rate & & & 1.000 \\
\hline
\end{tabular}

What accounts for this high predictability of EREITs and small cap stocks? A portion of the answer lies in the fact that the cap rate variable is highly significant for equity REITs and small cap stocks but is not significant for value-weighted stocks and bonds. In other words, conditions in the real estate market not only influence the returns of equity REITs but also affect the returns of small cap stocks. Surprisingly, the dividend yield is not significant for EREITs even though it is significant, as expected, for all other assets. This lack of forecasting power of the dividend yield on the stock market with respect to REITs might be related to the requirement that REITs pay out almost all of their entire available cash flow. A positive sign exists for EREITs and small stocks on both the dividend yield and cap rate, which is consistent with exante expectations given the assumption that the cap rate should behave in a similar manner to the dividend yield. Prior studies suggest that the major movement in the dividend yield series is related to long-term business conditions and captures the same predictable component of return as the default spread. When business conditions are weak and futures are uncertain, the dividend yield forecasts high future expected returns while low returns are predicted when conditions are strong. And this high future expected returns represent compensation for holding risky assets during time of high uncertainty and economic recession. At the outset, one might suspect that this finding might be due to the correlation between the dividend yield and the cap rate. However, the relatively moderate correlation between the Div. Yield and the CapRate state variables of $.545\left(r^{2}=.297\right)$ implies that the dividend yield and the cap rate series do not track similar predictable components of returns. Moreover, both the dividend yield and the cap rate are significant for small stocks while only the latter forecasting variable is highly significant for EREITs. 
Table 2 Regression of the returns on each asset class at time $t+1$ on a January dummy, the yield on Treasury bills, the spread between the yield on AAA corporate bonds and the yield on T-bills, the dividend yield for the overall stock market, and the cap rate on real estate all at time $t$.

\begin{tabular}{|c|c|c|c|c|c|c|c|c|c|c|c|}
\hline \multirow[b]{2}{*}{ Asset Class } & \multicolumn{11}{|c|}{ 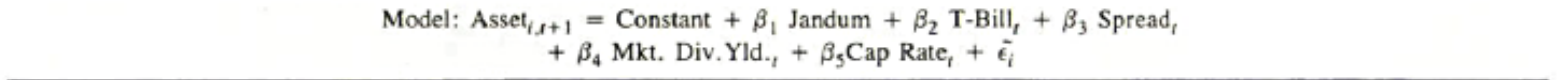 } \\
\hline & Constant & Jandum & T-Bill & Spread & Div. Yld. & Cap R & DW & $\mathrm{R}^{2}$ & $\begin{array}{c}\mathrm{R}^{-2} \\
\text { (Div.Yld.) }\end{array}$ & $\begin{array}{c}\bar{R}^{2} \\
(\text { CapR })\end{array}$ & $\begin{array}{l}\bar{R}^{-2} \\
\text { F Test }\end{array}$ \\
\hline VW stocks & $\begin{array}{l}-7.346 \\
(-2.10)\end{array}$ & $\begin{array}{c}1.841 \\
(1.57) \\
0.130\end{array}$ & $\begin{array}{r}-0.583 \\
(-3.02) \\
1.272\end{array}$ & $\begin{array}{r}0.021 \\
(0.10) \\
0.001\end{array}$ & $\begin{array}{l}1.429 \\
(2.12) \\
0.363\end{array}$ & $\begin{array}{c}0.703 \\
(1.64) \\
0.003\end{array}$ & 1.86 & .087 & 0.075 & 0.067 & $\begin{array}{r}0.619 \\
(0.43)\end{array}$ \\
\hline Equity REITs & $\begin{array}{r}-9.451 \\
(-2.79)\end{array}$ & $\begin{array}{c}5.277 \\
(4.63) \\
0.512\end{array}$ & $\begin{array}{r}-0.633 \\
(-3.38) \\
0.718\end{array}$ & $\begin{array}{r}-0.094 \\
(-0.44) \\
0.007\end{array}$ & $\begin{array}{c}0.962 \\
(1.47) \\
0.079\end{array}$ & $\begin{array}{c}1.121 \\
(2.69) \\
0.397\end{array}$ & 1.79 & .175 & 0.146 & 0.166 & $\begin{array}{l}8.500^{*} \\
(0.00)\end{array}$ \\
\hline Govt. bonds & $\begin{array}{l}-1.932 \\
(-0.80)\end{array}$ & $\begin{array}{r}-0.668 \\
(-0.82) \\
0.049\end{array}$ & $\begin{array}{c}0.121 \\
(0.90) \\
0.155\end{array}$ & $\begin{array}{c}0.404 \\
(2.63) \\
0.770\end{array}$ & $\begin{array}{c}1.447 \\
(3.11) \\
1.056\end{array}$ & $\begin{array}{r}-0.414 \\
(-1.39) \\
0.321\end{array}$ & 1.89 & .066 & 0.056 & 0.021 & $\begin{array}{r}0.030 \\
(0.86)\end{array}$ \\
\hline Small stocks & $\begin{array}{l}-13.237 \\
(-2.88)\end{array}$ & $\begin{array}{c}5.398 \\
(3.49) \\
0.312\end{array}$ & $\begin{array}{r}-0.885 \\
(-3.49) \\
0.818\end{array}$ & $\begin{array}{r}-0.097 \\
(-0.33) \\
0.004\end{array}$ & $\begin{array}{c}2.659 \\
(3.00) \\
0.351\end{array}$ & $\begin{array}{c}1.150 \\
(2.03) \\
0.244\end{array}$ & 1.76 & .165 & 0.148 & 0.128 & $\begin{array}{r}1.550 \\
(0.22)\end{array}$ \\
\hline
\end{tabular}

Notes: Regression coefficients are given by the first line of each row, while the $t$-statistics are given in parenthesis in the second row. The incremental contribution of each independent variable to the explained variance of the returns for each asset class is reported in the third row.

1. The summation of the incremental variance terms might exceed one due to the omission of the covariance terms. The incremental contribution of each independent variable to the explained variance of the returns for each asset class is computed using the following equation:

$$
\text { Incremental Contribution to Explained Variance }(\%)=\sum_{i=1}^{5} \frac{a_{i}^{2} \sigma_{i}^{2}}{\left(\sigma_{y}^{2}-\sigma_{\epsilon}^{2}\right.} \text { where the } a_{i} \text { 's are from the regression: } y=a+a_{1} x_{1}+a_{2} x_{2}+\ldots+a_{5} x_{5}+\epsilon .
$$

2. DW is the Durbin-Watson statistic

3. $\overline{\mathrm{R}}^{2}$ (Div. Yld.) is the $\overline{\mathrm{R}}^{2}$ obtained from estimating the model excluding the CapR variable but including the Div. Yld.

4. $\overline{\mathrm{R}}^{2}$ (CapR) is the $\mathrm{R}^{2}$ obtained from estimating the model excluding the Div. Yld. variable but including the CapR.

5. F test: The F test tests whether the coefficient of the CapR and the coefficient of the Div. Yld. are the same, e.g., tests if these two variables convey the same (identical) information.

Given the moderate correlation between the cap rate and divided yield variables in table 1 of .546 , we also performed several auxiliary regressions in which we excluded the cap rate (dividend yield) but included the dividend yield (cap rate) variable to determine whether the dividend yield variable picks up all of the cap rate information for EREITs. In addition, we also perform an $\mathrm{F}$ test to see if the coefficient associated with the cap rate and the coefficient corresponding to the dividend yield are identical. If they are different, then those variables contain different information. The results from the auxiliary regressions and $\mathrm{E}$ tests are reported in the last 3 columns of table 2 . The $\bar{R}^{2}$ columns reveal that movements in the cap rate contains unique information for the movements of EREITs and, to a lesser extent, movements in small cap stocks. More specifically, we can observe that the R-bar squared decreases from .175 to .146 when the cap rate is excluded from the EREIT estimation equation but only a minimal decrease in R-squared is evident when the dividend yield variable is omitted from the model. In contrast, fluctuations in the dividend yield are more informative in accounting for movements in the returns on bonds and stocks, especially small cap stocks. When the model is estimated without dividend 
yields, the amount of variation accounted for by the model drops anywhere from .02 to .045 for stocks and bonds. Moreover, the results of the $\mathrm{F}$ test show that we cannot reject that hypothesis that the coefficients associated with the cap rate and divided yield variables are the same for large cap stocks, bonds, and small cap stocks. However, we can reject this proposition for equity REITs. In other words, fluctuations in the cap rate does incorporate uniquely real-estate- related information at least with respect to EREITs but not necessarily for other asset classes.

To facilitate a better understanding of dividend yields and the cap rate, we also plot the two series in figure 1. It is easy to see that the dividend yield displays a stronger high frequency variation than cap rate, while the later exhibits a lower frequency variation. Thus, the two variables contain different information on the state of the economy and play different roles in predicting asset returns.

The spread variable, which tracks in part a maturity premium in expected returns, is highly significant for bonds but it isn't significant for other assets, including EREITs. Given this observation, together with the result that Div.Yld. is the only other variable that is significant for bond, suggests that the forecasting variables responsible for the predictable component of bond returns do not predict EREIT returns. This suggests that EREITs do not resemble bonds, and therefore bonds are not part of the hybrid nature of equity REITs.

As expected, the T-bill variable is significant for all stock categories but not bonds, which is consistent with the studies of Fama and Schwert (1977) and Campbell (1987). The nature of this relationship is negative, suggesting that stocks inclusive of EREITs exhibit "perverse" inflation behavior. This finding supports the results of Chan, Hendershott, and Sanders (1990). The addition of a dummy variable to capture the January seasonality impact has an important positive effect on EREITs and small cap stocks, but this January effect is not evident for value-weighted stocks or bonds. More specifically, the January effect accounts for 5 percent of the excess returns per year in EREITs and small cap stocks after taking into account the time variation in business conditions captured by the T-bill, term spread, the dividend yield, and the cap rate. This finding of a January effect is consistent with the finding of Col well and Park (1990) and suggests that this seasonality effect cannot be explained by variations in business condition variables. 


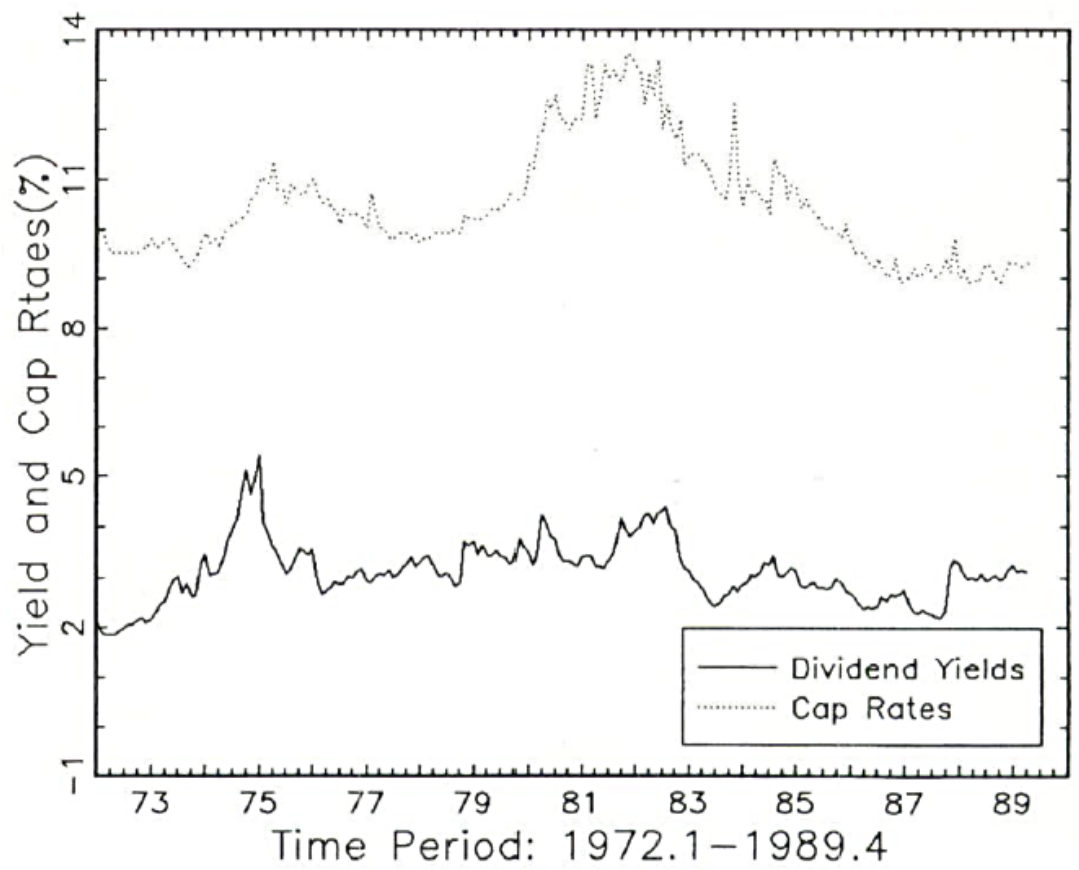

Figure 1 Dividend Yield and Cap Rates

A complementary perspective on why EREITs are similar to small cap stocks is obtained from marginal effects calculations, reported in the third row for each asset class in table 2 . The analysis of the incremental contribution of each forecasting variable to the explained variance of the returns for each asset class reveals that the January effect, the T-bill, and the cap rate are among the most important variables for both EREITs and small cap stocks in terms of accounting for the variation in returns for these asset classes. For both EREITs and small cap stocks, fluctuations in the T-bill are the most influential factor on the respective movements in returns. The January effect is the next most important catalyst for EREITs and the third most influential component for small cap stocks. The cap rate is the third element of relative importance for EREITs, accounting for almost 40 percent of the explained variation in EREIT returns. Approximately 24 percent of the fluctuation in small cap returns also arises from variations in the cap rate. Although deviations in the dividend yield represent the second most influential characteristic for small cap stocks, they are of relatively little importance in accounting for changes in EREIT returns. The marginal contribution analysis also reveals that while variations in the Tbill and dividend yield are also important for large cap stocks as well as small cap stocks, neither the January effect nor the cap rate acts as a catalyst for swings in large cap stocks. For bonds, the dividend yield is the most important factor, followed by the spread variable in accounting for movements in bond returns. 
In summary, the preceding evidence in table 2 suggests that EREITs are hybrid assets similar in nature to small cap stocks. Even though EREITs resemble small cap stocks, different factors are responsible for the predictable component of excess EREIT returns since dividend yields are not useful as a forecasting variable. Moreover, the cap rate appears to have more of an influence on EREIT returns relative to the returns on small cap stocks. These differences result in EREITs having a larger predictable component of excess returns relative to other assets.

A visual impression of the results in table 2 is given in figure 2 and figure 3 . Figure 1 plots the actual excess returns on EREITs $\left(\tilde{r}_{i, t+1}\right)$ and the conditional expected excess return $\left[E_{t}\left(\tilde{r}_{i, t+1}\right)\right]$ using a dotted line and a solid line, respectively. Figure 2 shows that the expected excess return, which is assumed to be constant in prior studies, does vary over time. In fact, the sign of $E_{t}\left(\tilde{r}_{i, t+1}\right)$ changes over time, taking on negative values in some time periods and positive values in other periods. In addition, even though the volatility of the actual EREIT returns is greater in the 1970 s relative to the 1980s, which is consistent with prior studies, the variation in the conditional risk premium does not appear to be changing over time. This implies that for the latter time period, a large proportion of EREIT returns are predictable with the $\mathrm{R}^{2}$ in table 2 revealing that the predictable portion of return, $E_{t}\left(\tilde{r}_{i, t+1}\right)$, accounts for 17.5 percent of the variation in $\left(\tilde{r}_{i, t+1}\right)$ over the entire study period.

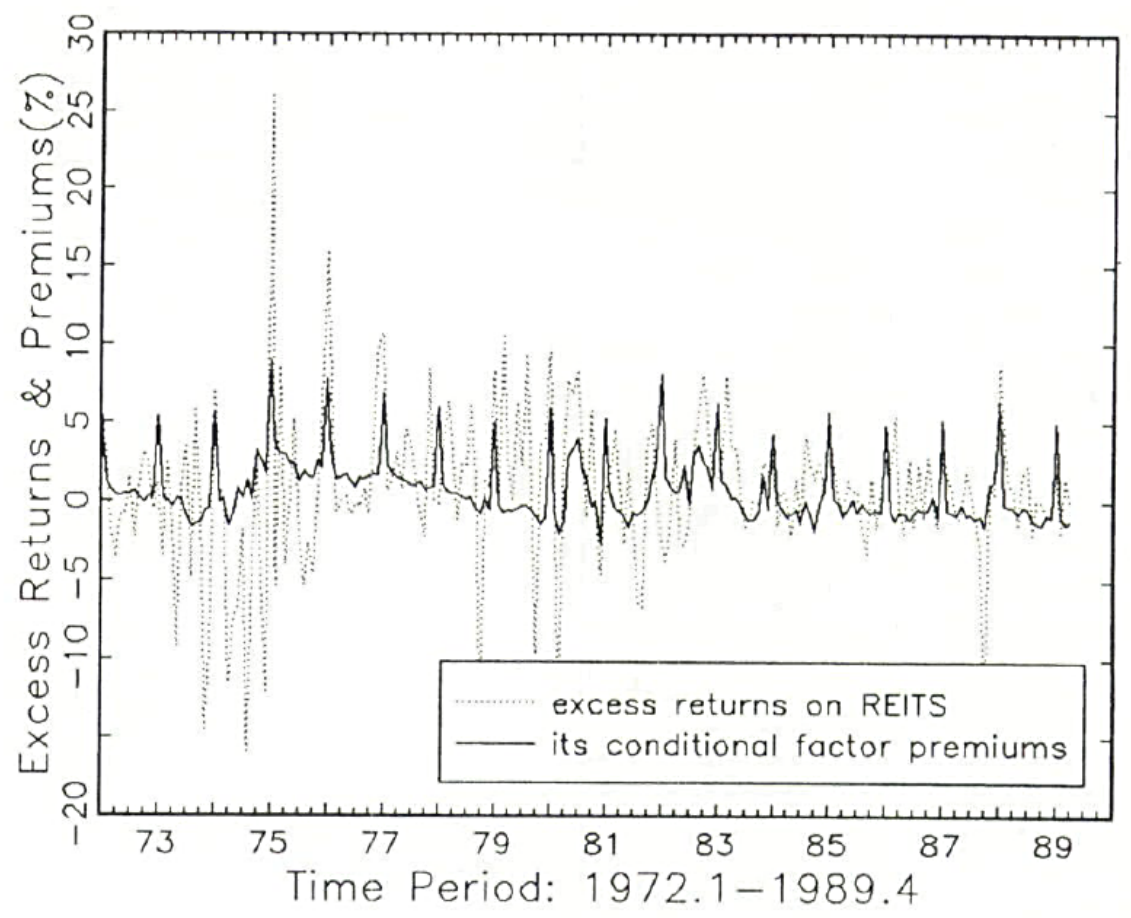

Figure 2 Excess Returns on REITs and Conditional Risk Premiums 
Figure 3 shows the co-movement of the expected excess return, $E_{t}\left(\tilde{r}_{i, t+1}\right)$, for value-weighted stocks, EREITs, government bonds, and small cap stocks. An inspection of this figure reveals that the conditional risk premiums for value-weighted stocks, EREITs, and small cap stocks appear to move in tandem. The strength of this co-movement is not as pronounced for bonds. Figure 3 also shows that the monthly predictable risk premiums on the EREIT can be as high as 12 percent. In terms of volatility in the expected excess returns, the biggest volatility in $E_{t}\left(\tilde{r}_{i, t+1}\right)$ is associated with small cap stocks followed by EREITs, value-weighted stocks, and government bonds, respectively. The predictability in expected excess return that we document does not necessarily imply that the market is inefficient but rather could reflect rational pricing in an efficient market under different business conditions. However, the huge variation in expected excess returns or the risk premiums is still astonishing given the seemingly stable risk tolerance of market participants and the stable payoff structure for portfolio fund managers.

A question that naturally arises from examining the excess returns on various assets relative to the five forecasting variables is the extent to which our model is well specified. The evidence appears to support the notion that our model is well specified since the residual $\left(\epsilon_{i}\right)$ that remains after the time varying risk premiums are accounted for has a small if not negligible serial correlation.

In table 3 we report our estimates of the restricted versions of the model [Equation (6)] shown in table 2. The estimation method used is the GMM procedure of Hansen, which adjusts not only for heteroskedasticity but also for serial correlation in the error terms and allows for contemporaneous correlation among the error terms across securities. In panel A, we estimate the regression system under the assumption that there is only one "priced" systematic factor $\tilde{f}_{1, t+1}$, in the economy ( $\left.\mathrm{K}=1\right)$. With beta normalized to be 1 for value-weighted stocks, we observe that the beta for EREITs are higher than these value-weighted stocks but are smaller than small cap stocks. Not surprisingly, bonds have the lowest beta of all asset classes. The chi-square test in table 3 indicates that a one factor model is not rejected by the data at a 5 percent significance level. Figure 4 gives an alternative visual presentation of the results reported in panel $A$ of table 3 . The figure plots the unrestricted fitted values of $E_{t}\left(\tilde{r}_{i, t+1}\right)$ for EREITs, using a solid line and a dashed line, respectively. Figure 4 shows that the expected excess returns estimated under the rank restriction closely resemble those estimated without the restriction. The figure also shows that the single-factor latent-variable model provides a fairly good fit of the data and results in an impressive degree of movement in expected excess returns. 


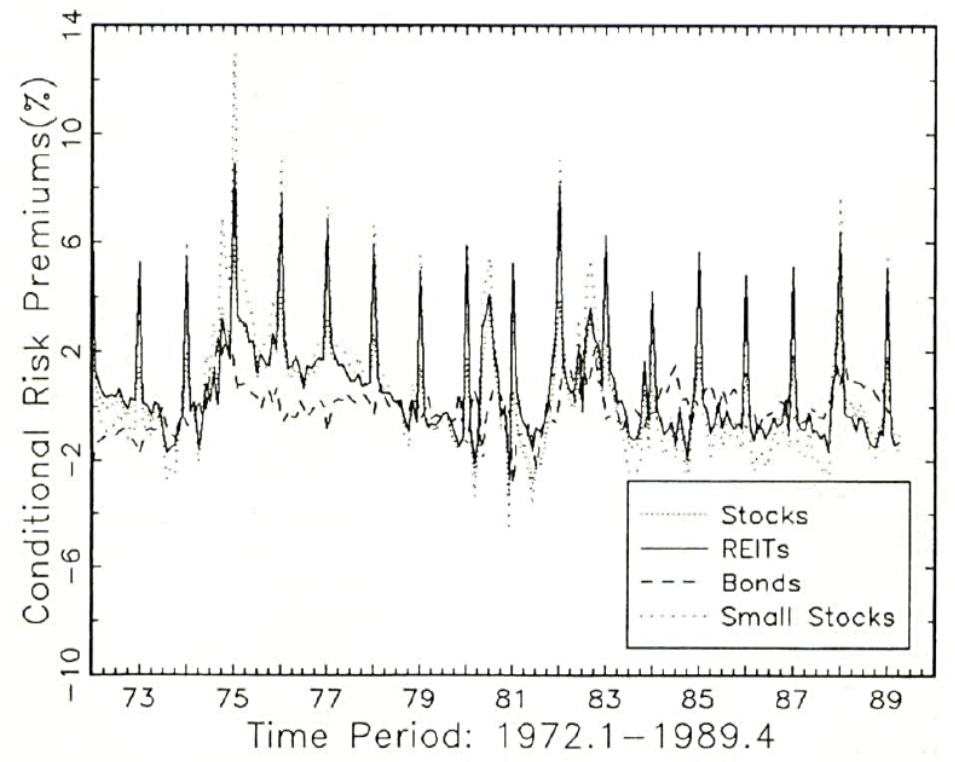

Figure 3 Conditional Risk Premiums on Different Assets

Table 3 Estimation of the Latent Variable Model (4) with the Rank Restriction of Equation (5) Imposed

$$
\begin{aligned}
E_{t}\left[\tilde{r}_{i, t+1}\right] & =\sum_{k=1}^{K} \beta_{i k} \sum_{n=1}^{L} \theta_{k n} X_{n t}=\sum_{n=1}^{L} \alpha_{i n} X_{n t} \\
\alpha_{i j} & =\sum_{k=1}^{K} \beta_{i k} \theta_{k j} .
\end{aligned}
$$

A. The number of systematic factors in the economy equals $1(K=1)$.

$$
\beta_{i 1}
$$

Estimated beta coefficient for the following assets:

Excess return on value-weighted portfolio (VW)

Excess return on REITs portfolio (REITs)

Excess return on government bond portfolio (Bond)

Excess return on small stock portfolio (SS)

0.253

0.109

$\chi^{2}$-statistic of the rank restriction (5): $24.2578(\mathrm{DF}=15)$

Significance level:

$$
\mathrm{P}=0.061
$$

B. The number of systematic factors in the economy equals two $(K=2)$.

$$
\beta_{i 1} \quad \text { S.D. } \quad \beta_{i 2}
$$

S.D.

Estimated beta coefficient for the following assets:

Excess return on value-weighted portfolio (VW)

Excess return on government bond portfolio (Bond)

Excess return on REITs portfolio (REITs)

Excess return on small stock portfolio (SS)

$\begin{array}{lccc}1.000^{*} & - & 0.000^{*} & - \\ 0.000^{*} & - & 1.000^{*} & - \\ 1.636 & 0.333 & -0.991 & 0.516 \\ 1.934 & 0.269 & -0.317 & 0.518\end{array}$

$\chi^{2}$-statistic of the rank restriction (5): $7.778(\mathrm{DF}=8)$

Significance level:

$$
\mathrm{P}=0.455
$$

Notes: Asterisks $\left(^{*}\right)$ indicate that these numbers are normalized to be 1 or 0 . The sample period for this table is 1972.1-1989.4, with 208 observations. The standard errors reported here have been corrected for heteroskedasticity using the general method of moments (GMM) of Hansen (1982). 
But the single-factor model is rejected if one uses a 10 percent significance level $(p=0.061)$. Thus, we also estimate a two-factor model, the results of which are reported in panel B of table 3 . We normalize the value-weighted stock to have a beta of one on the first factor and a beta of zero on the second factor, and we normalize bonds to be the reverse. Under such normalization, we see that small cap stocks are more sensitive than EREITs to pervasive forces that affect value-weighted stocks, while EREITs appear to be a better hedge instrument than small stocks against systematic shocks that affect bond excess returns. From this perspective, it is striking to see that EREITs are actually less similar to bonds than small cap stocks are. The rank restriction test suggests that the two-factor model is not rejected by data.

\section{Summary and Conclusions}

In this study we analyze the predictability of expected returns on equity REITs, using a multifactor model with time varying risk premiums that decomposes excess asset returns into two parts: expected returns and unexpected excess returns. In the process, the hybrid nature of EREITs is examined. Our main finding is that the expected excess returns are more predictable for equity REITs than for small cap stocks, value-weighted stocks, and bonds. Moreover, the graphical evidence indicates that the risk premiums vary substantially over time and suggests that in certain time periods it might pay to take risks. In other words, market timing might prove to be a fruitful endeavor. While prior studies have found that EREIT returns resemble large cap stocks, we find that returns on EREITs move more closely with small cap stocks. Interestingly, we also find that real estate market conditions influence small cap stocks in addition to EREITs. We also find evidence that EREIT returns do not resemble bond returns even though the cash flow portion of equity REITs resembles interest payments on bonds. Moreover, to some extent, EREITs are actually less similar to bonds than are small cap stocks. Another finding of the study is that these preceding results are consistent with the view that the changing price of risk of a single systematic factor affecting returns on all assets is an important determinant of expected asset returns. 


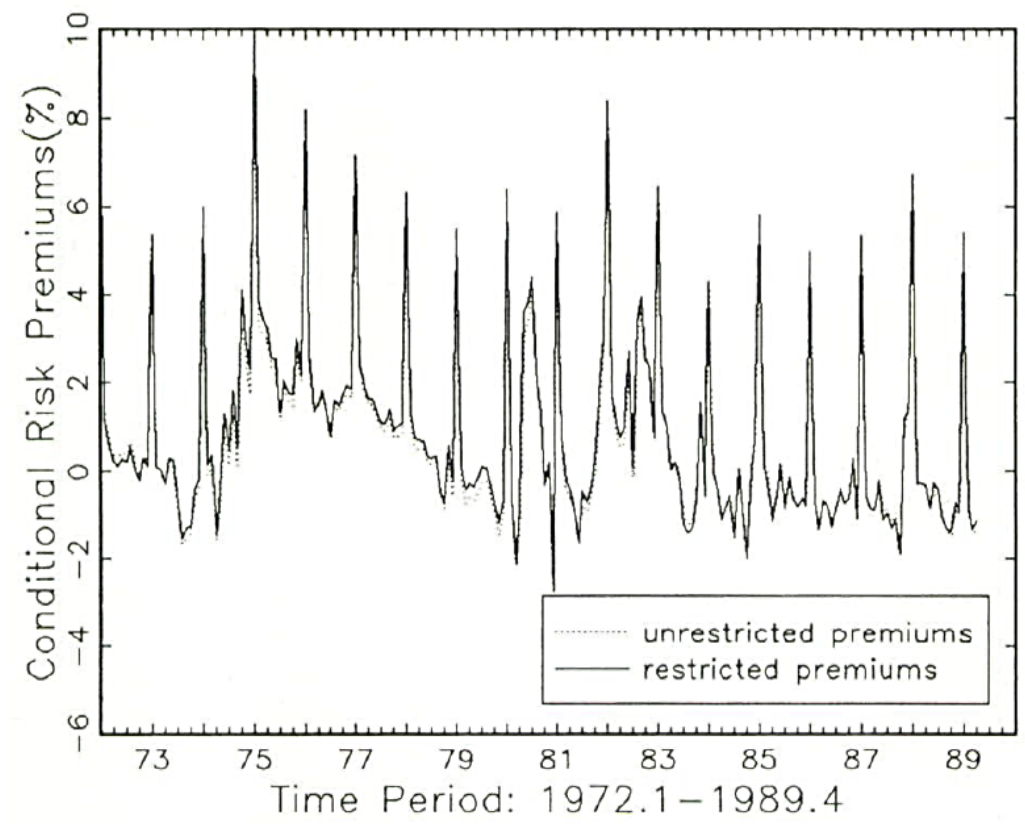

Figure 4 Restricted and unrestricted conditional risk premiums

\section{Acknowledgments}

We would like to thank John Campbell for letting us use his latent variable model algorithm, and Doug Herold and Wayne Ferson for providing data to us on real estate cap rates and business condition variables, respectively. We also thank William M. Gentry for helpful comments.

\section{Appendix: Elaboration of the Estimation Procedure}

After Hansen, we first construct $a N x L$ sample mean matrix: $G_{T}=U^{\prime} X \mid T$, where $E\left(U^{\prime} X\right)=0$ because the error term in system (6) has conditional mean zero, given the instruments $X$ from equation (4). Next, we stack the column vector on top of each other to obtain a NL $x 1$ vector of $g_{T}$. A two-step algorithm is then used to find an optimal solution for the quadratic form, $g_{T}{ }^{\prime} W^{-1} g_{T}$, by minimizing over the parameter space of $(\theta, \alpha)$. In the first step, the identity matrix is used as the weighting matrix $W$. After obtaining the initial solution of $\theta_{O}$ and $\alpha_{O}$, we next calculate the residuals $\mu_{1}$ and $\mu_{2}$ from the system of equations in (6) and construct the following weighting matrix:

$$
W=\frac{1}{T} \sum_{t}\left(u_{t} u_{t}^{\prime}\right) \otimes\left(z_{t} z_{t}^{\prime}\right),
$$


where $\otimes$ is the Kronecker product. Next, we use the weighting matrix in equation (A.I) to resolve the optimization problem of minimizing $g_{T}{ }^{\prime} W^{-1} g_{T}$ over the choice of $(\theta, \alpha)$. Hansen proved that under the null hypothesis (i.e., when the model is correctly specified). $T g_{T}{ }^{\prime} W^{-1} g_{T}$, is asymptotically chi-square distributed, with the degrees of freedom equal to the difference between the number of orthogonality conditions and the number of parameters estimated: $N \times L-[K \times L+(N-K) \times K]=\{N-K)(L-K)$, where $N$ is the number of assets studied, $K$ is the number of factor loadings, and $L$ is the number of forecasting variables.

After obtaining the weighted sum of squared residuals, we perform a chi-square test to determine if the data reject the restricted regression system (6). If they do not, we can use (6) to study how much of the variation-in-asset returns these forecasting variables predict. We can also interpret the regression results as to what extent these economic conditions affect conditional factor risk premiums. Even if the overidentifying restrictions of equation (5) are rejected, the estimated coefficients may still be of interest. The fitted values from (5) are the best possible forecasts of asset returns subject to the restriction that there are $K$ major systematic factors in the economy. They can thus be interpreted as estimates of a common component in expected asset returns.

\section{References}

Campbell, John Y. "Stock Returns and the Term Structure" Journal of Financial Economics 18 (1987), 373399.

Campbell. John Y. "Intertemporal Asset Pricing Without Consumption." Working Paper, Princeton University, 1990.

Campbell. John Y., and Hamao, Yasushi, "Predictable Stock Return in the United States and Japan: A Study of Long-Term Capital Market Integration," Working Paper, Princeton University. 1991.

Chan, K.C., Hendershott, Patric, and Sanders, Anthony. "Risk and Return on Real Estate: Evidence from Equity REITs," AREUEA Journal 18 (1990), 431-452.

Chen, Nai-fu, Roll, Richard, and Ross, Stephen. "Economic Forces and the Stock Market." Journal of Business, 59 (1986), 386-403.

Colwell, Peter, and Park, Hun Y, "Seasonality and Size Effects: The Case of Real-Estate-Related Investment. Journal of Real Estate Finance and Economics 3 (1990), 251-260,

Connor, Gregory, and Korajczyk, Robert A. "Risk and Return in an Equilibrium APT: Application of a New Test Methodology." Journal of Financial Economics 21 (1988), 255-289. 
Corgel, John B., and Rogers, Ronald C. -Market Trading Characteristics of REITs: Tests of the Stock Market and Hybrid Securities Hypotheses." Working Paper, Cornell University, 1991.

Fama, E., and French, K. "Dividend Yields and Expected Stock Returns." Journal of Financial Economics 22 (1988), 3-25.

Fama, E., and French, K. "Business Conditions and Expected Return on Stocks and Bonds," Journal of Financial Economics 25 (1989), 23-49.

Fama, E., and Schwert, G. William, "Asset Returns and Inflation," Journal of Financial Economics 5 (1977) 115-146.

Ferson, W. "Changes in Expected Security Returns, Risk, and Level of Interest Rates." Journal of Finance 44 (1989), 1191-1217.

Ferson, W, "Are the Latent Variables in Time-Varying Expected Returns Compensation for Consumption Risk?" Journal of Finance 45 (1990), 397-430.

Ferson, W., and Harvey, C. "The Variation of Economic Risk Premiums." Journal of Political Economy (forthcoming, 1990).

Ferson, Wayne, Kandel, Shmuel and Stambaugh, Robert. "Test of Asset Pricing with Time-Varying Expected Risk Premiums and market Betas," Journal of Finance 42 (1987), 201-219.

Geltner, David, "Risks and Returns m Commercial Real Estate: An Exploration of Some Fundamental Relationships," Doctoral dissertation thesis, Massachusetts institute of Technology, 1989.

Gibbons, Michael R., and Ferson, Wayne, "Testing Asset Pricing Models with Changing Expectations and an Unobservable Market Portfolio." Journal of Financial Economics 14 (1985), 217-236.

Giliberto, S. Michael. "Equity Real Estate Investment Trust and Real Estate Returns." Journal of Real Estate Research 5 (1990), 259-263.

Gyourko, Joseph, and Keim, Donald, "What Does the Stock Market Tell Us About Real Estate Returns?" Working Paper, The Wharton School, 1991.

Harvey, Campbell R, "Time-Varying Conditional Covariances in Tests of Asset Pricing Models." Journal of Financial Economics 24 (1989), 289-317.

Keim, Donald B, "Size Related Anomalies and Stock Return Seasonality: Empirical Evidence." Journal of Financial Economics 12 (1983), 13-32.

Keim, D., and Stambaugh, R. "Predicting Returns in the Stock and Bond Markets." Journal of Financial Economics 17 (1986), 357-390.

Mei, Jianping. "New Method for the Arbitrage Pricing Theory and the Present Value Model," Doctoral dissertation, Princeton University, 1990. 
Mengden, Ann, and Hartzell, David J. "Real Estate Investment Trusts-Arc They Stocks or Real Estate?" Stock Research-Real Estate, Solomon Brothers Inc., 1986.

Nourse, Hugh 0. "The 'Cap Rate' 1966-1984: A Test of the Impact of Income Tax Changes on Income Property." Land Economics 63 (1987), 147-152.

Roll, Richard, and Ross. Stephen A, "An Empirical Investigation of the Arbitrage Pricing Theory," Journal of Finance 35 (1980), 1073-1103.

Ross, Stephen, "The Arbitrage Theory of Capital Asset Pricing." Journal of Economic Theory 13 (1976), 341-360.

White, Halbert. "A Heteroskedasticity-Consistent Covariance Matrix Estimator and a Direct Test for Heteroskedasticity." Econometrica 48 (1980), 817-838.

\footnotetext{
${ }^{1}$ See, for example, Campbell (1987), Campbell and Hamao (1991). Chen, Roll, and Ross (1986). Fama and French $(1988,1989)$. Fama and Schwert (1977), and Keim and Stambaugh (1986). These papers find that the dividend yield on the stock market, the January effect, the return on Treasury bills, and the long-term yield spread are useful in predicting excess stock returns among other variables.

${ }^{2}$ An equity REIT is a mutual fund for investors who want to participate in the ownership of real estate, A REIT is not taxed on distributed taxable income if it satisfies certain provisions, including the fact that at least 95 percent (90 percent prior to 1980) of net annual taxable income must be distributed to shareholders.

${ }^{3}$ One exception to this is the study by Chan, Hendershott, and Sanders (1990) who examine EREITs using an APT framework. However, that study does not specifically focus on the predictability of EREIT returns. In addition, the study assumes that the risk premiums are constant over time, while the current study allows the risk premiums to vary over time, The current study also tests whether there are any priced factors that are unobservable/latent using the technique in Campbell and Hamao (1991).

${ }^{4}$ Prior studies have concentrated on the second and third components on the righthand side of equation (1) assuming that $E_{t}\left(\tilde{r}_{i, t+1}\right)$ is constant. These studies focus on the closeness of EREITs to stocks in terms of beta $(\beta)$. that is. in terms of similar sensitivity toward the systematic forces. The idiosyncratic term is generally ignored here because the risk can be diversified and should not affect risk premiums.

${ }^{5}$ Equation (2) states that the conditional expected rate of return should be linear function of factor risk premiums, with the coefficients equal to the betas of each asset. This type of linear pricing relationship can be generated by a number of intertemporal asset pricing models, under either a no-arbitrage opportunity condition or through a general equilibrium framework. See, for example, Ross (1976), Campbell (1990), and Connor and Korajczyk (1989). ${ }^{6}$ For more details on this model, see Hansen and Hodrick (1983), Gibbons and Ferson (1985), Campbell (1987), and Ferson and Harvey (1990).

${ }^{7}$ Fama and French (1989) also uses the spread between yields of a low-grade, long-term corporate bond and a long term Treasury bond to capture the default risk in the financial market. However, they find the variable to be capturing the same information as the dividend yield. Thus, we only include dividend yield in the study.

${ }^{8}$ Nourse (1987) has used the cap rate in testing the impact of income tax changes on income property, Nourse uses the Ellwood representation of the cap rate in which the cap rate represents a weighted average cost of capital with an adjustment for equity buildup and an adjustment for anticipated increases or decreases in value.

${ }^{9}$ By taking conditional expectations of equation (2), it is straightfoward to show that the rank restrictions hold in the same form when a subset of the relevant information is used. Thus, if the coefficients in equation (4) are subject to the restrictions in equation (5) under the true information vector used by the market, they will be subject to the same form of restrictions in equation (5) if a subset of this vector is included in the information set. Similarly, if the test using the full set of the market's information does not reject the K-factor model, then the test
} 
using a subset of the market's information should not reject the model either. A more detailed elaboration of this robustness issue is discussed in Campbell (1987) and Ferson (1989).

${ }^{10}$ This is a significant improvement over the existing methodology which generally assumes constant risk premiums. This assumption is in contrast to a large body of evidence on time-varying risk premiums, which has been documented extensively by Campbell (1987), Fama (1990), Fama and French (1989), Ferson, Kandel, and Stambaugh (1987), and Kandel and Stambaugh (1990), among others. It is certainly possible that the poor performance of the multifactor model discovered by previous studies may due to the imposition of this restrictive assumption.

${ }^{11}$ Unfortunately, the ACLI does not break down monthly cap rates by type of real estate. This is only done with respect to quarterly cap rates. The ACLI data used in the current study differ from that of Nourse (1987) in that Nourse uses quarterly cap rates as opposed to the monthly cap rates used in the current study. Critics of quarterly cap rate studies point out that one does not know which of the three months that comprise a quarter the quarterly cap rates are reflecting. This is not a problem with monthly cap rates.

${ }^{12}$ We thank an anonymous reviewer for valuable insight on this point. 